\title{
30. THE COMPRESSIVE MECHANICS OF ACCRETIONARY WEDGES APPLIED TO THE LEG 78A STUDY AREA NEAR BARBADOS 1
}

\author{
Dan M. Davis, Department of Earth and Planetary Sciences, Massachusetts Institute of Technology²
}

\begin{abstract}
Sites 541 and 542 of DSDP Leg 78A are very near the front of a large wedge of accreted sediments at the eastern edge of the Caribbean Plate where it overthrusts the downgoing crust of the Altantic Ocean. The mechanics of this wedge are considered in light of the Coulomb-wedge hypothesis of Davis et al. (1983), which regards the sediments of the wedge as analogous to soil being pushed by a bulldozer. The wedge deforms in order to attain and maintain its critical taper, at which it could stably ride over the downgoing plate. If it were allowed to maintain that taper without any erosion or accretion, then no significant internal deformation would be required for the wedge to ride over its décollement. The magnitude of this critical taper is a function of fluid pressures and the mechanical properties of the wedge and décollement. The narrow taper of the Barbados wedge is consistent with the evidence of high fluid pressures for the region, suggesting that its behavior is dominated by horizontal compression resulting from plate convergence. The hypothesis that the wedge is at or near compressive failure permits a description of the state of stress in the wedge. The borehole stability problems experienced at Sites 541 and 542 are consistent with the view (Hottman et al., 1979) that boreholes act as stress concentrators. The resulting stress concentration can initiate compressive failure of the borehole wall, and may have contributed to the borehole instability observed on Leg 78A.
\end{abstract}

\section{INTRODUCTION}

Sites 541 and 542 of DSDP Leg 78A are at the narrow frontal toe of the large accreting wedge of sediments located at the eastern edge of the Caribbean Plate between the plate boundary and the volcanic Lesser Antilles arc (Fig. 1). At this deformation front, ocean crust roughly $65 \mathrm{Ma}$ old is subducted to the west at a rate of $2.2 \mathrm{~cm}$ per year (Minster and Jordan, 1978). The sediments overlying the ocean crust are partially accreted onto the overlying plate. This accretion and the subsequent compression of the sediments have resulted in the development of an imbricate-thrusting accretionary wedge (Seely et al., 1974; Westbrook, 1975). The wedge has grown outward to the unusually great length of roughly $200 \mathrm{~km}$, and the trench has ceased to exist as a major bathymetric feature (Westbrook, 1982). Barbados, the only part of the wedge above sea level, is a local high point on the Barbados Ridge, which is near the back of the actively accreting wedge and runs parallel to the deformation front (Westbrook, 1982). The relatively undeformed sediments of the Tobago Trough lie to the west of Barbados. Beneath the Tobago Trough and the Lesser Antilles, the Wadati-Benioff zone steepens to a dip of roughly $35^{\circ}$, but under most of the accretionary wedge the contact between the downgoing and overlying plates has a dip of only about $5^{\circ}$.

There has been a longstanding debate over whether the thin-skinned mechanics of foreland fold-and-thrust belts and their marine analogs, accretionary wedges, result from compressional mechanics or from gravitationally induced flow comparable to that in a glacier.

\footnotetext{
${ }^{1}$ Biju-Duval, B., Moore, J. C., et al., Init. Repts. DSDP, 78A: Washington (U.S. Govt. Printing Office).

2 Present address: 220 Seismology Bldg., Lamont-Doherty Geological Observatory, Palisades, NY 10964.
}

The paradox of large overthrust sheets comprised of relatively weak rock (Smoluchowski, 1909) was solved somewhat by the discovery of the role of fluid pressure in thrust mechanics (Hubbert and Rubey, 1959). An understanding of the role of gravity in the flow of glaciers has encouraged the application of gravity-dominated models to thrust belts and accretionary wedges (Elliot, 1976). The wedge-like cross-sectional shape of these features has been shown (Chapple, 1978) to allow plastic overthrust bodies to be pushed over a weak basal décollement for great distances. It has been shown that a sufficiently tapered wedge of Coulomb material can be pushed over a décollement, no matter how long it may be (Davis and Suppe, 1980; Davis et al., 1983). This paper investigates the degree to which the available data concerning the Barbados accretionary wedge are consistent with a regional mechanics dominated by horizontal compression, as has been demonstrated (Davis et al., 1983) for the two-sided Taiwan wedge.

\section{COULOMB WEDGE MODEL}

The mechanics of the Barbados accretionary wedge can be considered as analogous to that of a wedge of soil being pushed by a bulldozer (Fig. 2). The bulldozer corresponds to the stable rearward parts of the overlying plate, and the earth which is beneath both the soil and the bulldozer corresponds to the underthrust plate. Let us list the forces acting on a wedge-shaped mass of sediments, such as an accretionary wedge. The first force results from a shear stress applied at the base. The magnitude we attribute to that shear stress depends upon the assumptions we make about rock strength. Laboratory measurements of rock strength under brittle deformation (Byerlee, 1978; Hoshino et al., 1972) and ductile flow (Goetze, 1978; Heard and Carter, 1968) at typical geological strain rates (Pfiffner and Ramsay, 1982) suggest that friction-dominated deformation controls the 


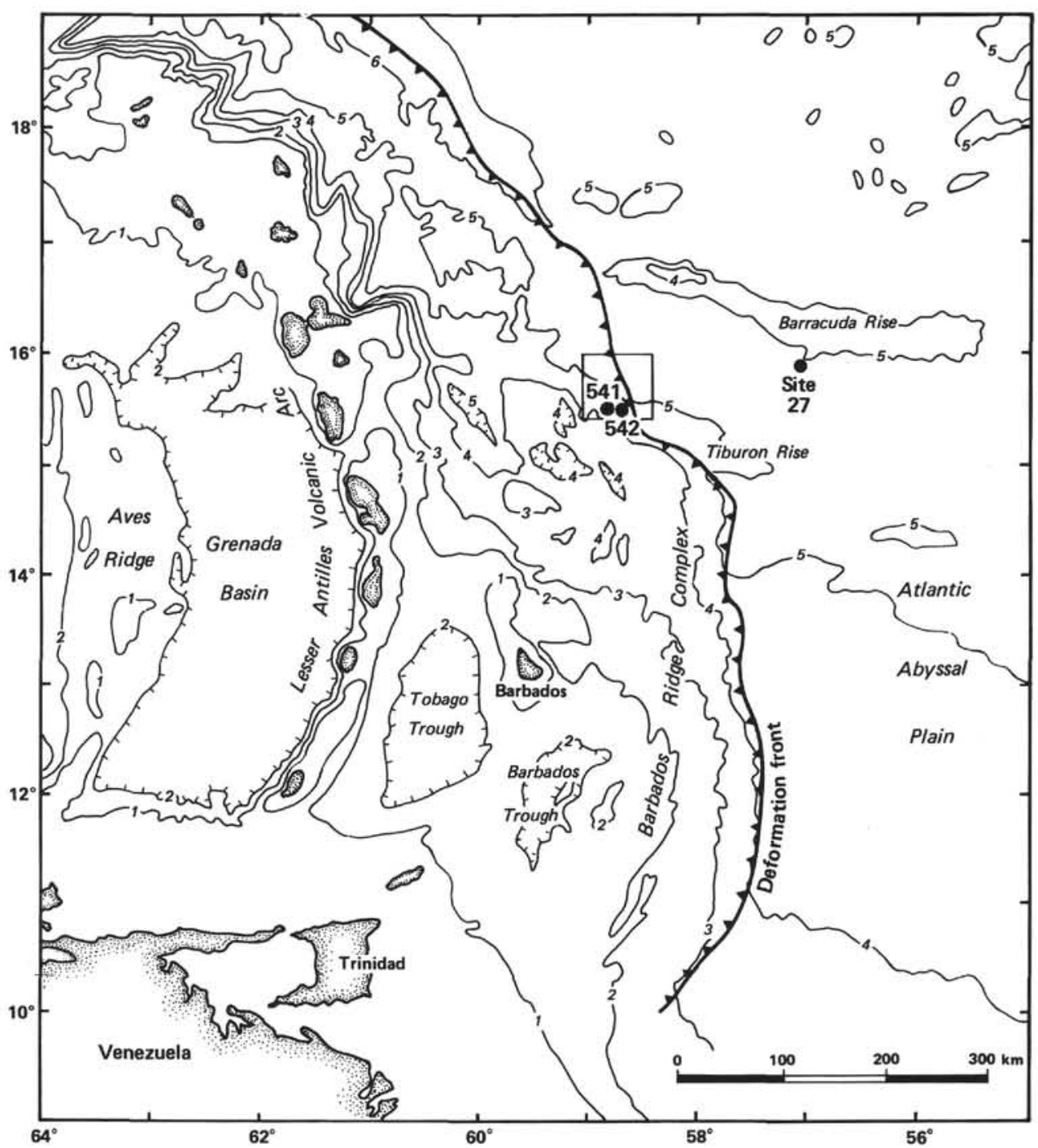

Figure 1. Map of the Lesser Antilles area showing locations of Sites 541 and 542 and the island of Barbados with respect to the overthrust boundary between the Caribbean Plate and the downgoing ocean crust of the Atlantic. (Depths in km.)

state of stress in the upper 10-15 km of the crust (Brace and Kohlstedt, 1980). Above the brittle-ductile transition, time-independent friction may be assumed to govern sliding along pre-existing faults, except very near the deformation front and at very shallow depths, where sediments are most likely to be unlithified. Byerlee (1978) finds that an extraordinarily wide variety of nonclay rocks exhibit sliding which closely matches the empirical "law"

$$
\tau_{b}=0.85 \sigma_{n}^{*} \quad\left(5 \mathrm{MPa} \leq \sigma_{n}^{*} \leq 200 \mathrm{MPa}\right)
$$

where $\tau_{b}$ and $\sigma_{n}^{*}$ are the shear stress and effective normal stress applied across a fault, in this case the basal décollement.

By inspecting a schematic diagram of an accretionary wedge, we can discern the nature of the remaining forces acting in the $x$-axis direction upon an element of the wedge (Fig. 2). We find that there is a component of force, acting in the $x$-direction, which results from the presence of a water overburden. The $x$-axis component of the stress corresponding to this overburden is equal to $\rho_{w} g D \tan (\alpha+\beta)$, where $\rho_{w}$ is the density of water, $g$, is the acceleration due to gravity, $D$, is the local depth of the water overburden, and $\alpha$ and $\beta$ are, respectively, the local dips of the base and upper surface of the wedge. In reality, neither the upper nor the lower boundary of an accretionary wedge is necessarily very smooth. However, the shorter wavelength undulations in the wedge have relatively little effect upon the overall state of stress in the wedge and can, as a first-order approximation, be ignored. There is also an $x$-axis component to the gravitational body force acting on the wedge segment. The magnitude of this component of the force balance is $\rho g H \sin \beta$, where $\rho$ is the bulk density of the wedge sediments and $H$ is the local thickness of the wedge. The sum of these forces must be balanced by the difference in total horizontal push applied to either side of the segment. Expressing this $x$-axis force balance in terms of stresses and gradients of stresses, we have 


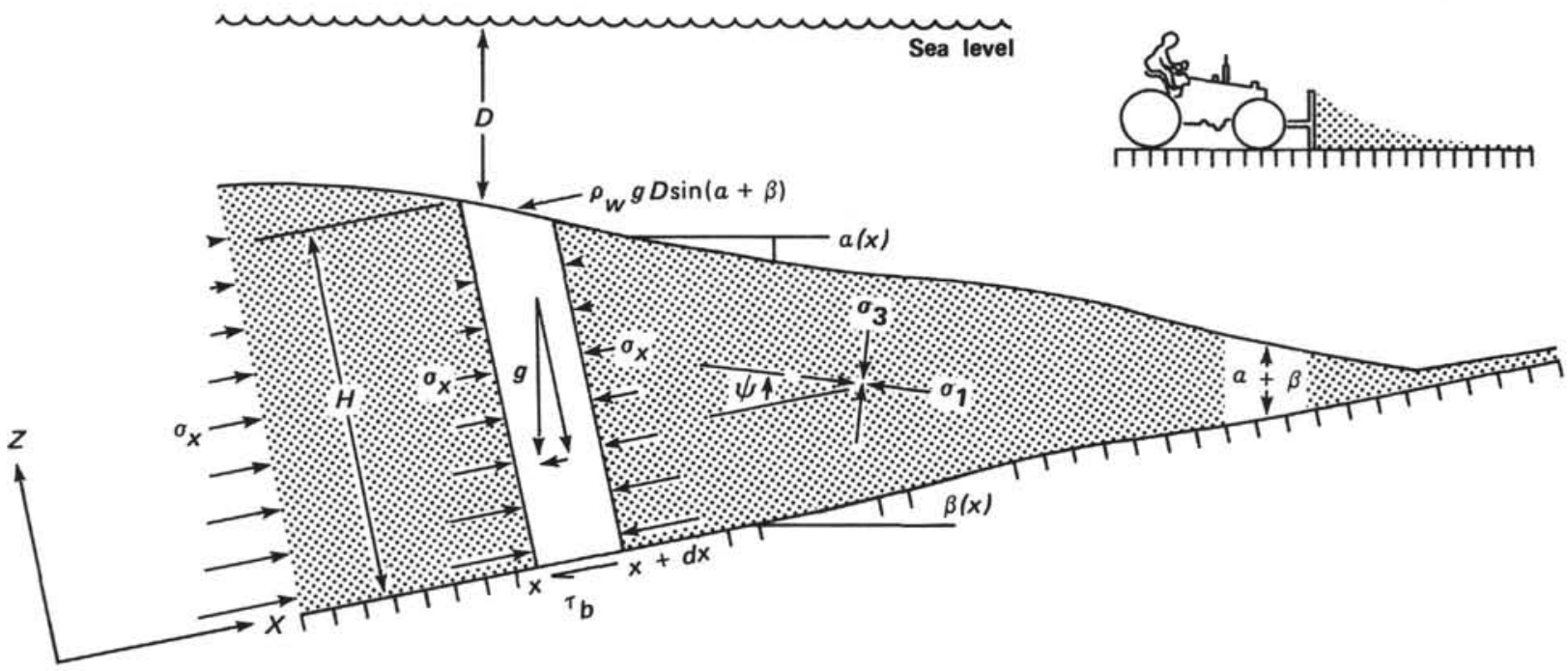

Figure 2. Schematic diagram of an accretionary wedge subject to horizontal compression and on the verge of Coulomb failure throughout. The forces acting on an arbitrary column of width $\delta x$ are shown (after Davis et al., 1983). See text for explanation and discussion.

$$
\tau_{b}+\rho_{w} g D \tan (\alpha+\beta)+\rho g H \sin \beta=\frac{\partial}{\partial x} \int_{0}^{H} \sigma_{x x}(x, z) d z
$$

where $\sigma_{x x}(x, z)$ is the $x$-axis component of stress at an arbitrary point in the wedge.

We must now determine the state of stress within the wedge. This is possible because we assume the wedge to be everywhere on the verge of horizontal compressive failure. Such failure, in the form of thrust faulting, tends to shorten and thicken the wedge, resulting in a larger wedge taper. The taper increases until the accretionary wedge, like a bulldozer wedge, can move en masse over the underlying surface, while remaining just on the verge of compressive failure.

In keeping with a large body of experimental and theoretical results (Brace and Kohlstedt, 1980; Kirby, 1980; Byerlee, 1978; Meissner and Strehlau, 1982), it is assumed that rock deformation in the upper lithosphere is governed by pressure-dependent, time-independent Coulomb behavior, that is, by brittle fracture (Paterson, 1978) or frictional sliding (Byerlee, 1978). Failure of a Coulomb material occurs when the shear stress exceeds a value given by an expression containing two terms.

$$
\tau>S_{0}+\sigma_{n}^{*} \tan \phi
$$

$S_{0}$ is a depth-independent cohesive strength. The second term on the right side is a depth-dependent internal friction in which $\phi$ is the internal friction angle and $\sigma_{n}^{*}$ is the effective normal stress, which increases with depth. The cohesive term is important wherever the wedge is sufficiently thin that $S_{0} /(1-\lambda) \rho g z$, the ratio of the cohesive strength over the effective overburden, is not much less than one. Throughout most of the Barbados wedge, the depth-dependent term predominates, assuming that the cohesive strength and internal friction are consistent with laboratory measurements of typical sedimentary rocks (Hoshino et al., 1972). The assumption of Coulomb behavior is reasonable in light of the current un- derstanding of stress in the upper part of the crust. It is also a conservative assumption, in that it is mechanically most difficult to push a wedge with a strong frictional base, if one makes no extreme assumptions about fluid pressures along the basal décollement.

Fluid pressure plays an important role in Coulomb failure. To quantify the fluid pressure, we use a generalization of the coefficient $\lambda$ of Hubbert and Rubey (1959). The water table in the earth can be located at, below, or above the rock surface (Fig. 3). The case of a water table above the surface corresponds to that in a submerged accretionary wedge. In order to deal with this case, we define $\lambda$ in a more generalized manner. We let $\lambda$ be the ratio of fluid pressure change to the net increase in lithostatic overburden from the top surface of the wedge to any given depth within the wedge.

$$
\lambda=\frac{P_{f}-\rho_{w} g D}{\left|\sigma_{z z}\right|-\rho_{w} g D}
$$

where $P_{f}$ is pore pressure and $\sigma_{z z}$ is the vertical normal stress. We let $\lambda_{b}$ be the corresponding ratio along the basal décollement. It has been observed (Fertl, 1976) that, in general, $\lambda_{b} \geq \lambda$. But whereas fluid pressures have been directly measured in boreholes on Taiwan (Suppe and Wittke, 1977; Davis et al., 1983), the Barbados wedge does not have very well-constrained pore pressures (Moore and von Huene, 1980). Therefore we shall, in general, make the conservative assumption that there is no overthrust-easing sudden increase in the fluid pressure gradient at the basal décollement.

Cohesion is most important in controlling the taper of a thrust belt near its toe, where the wedge thickness is smallest (Davis and Suppe, 1980; Davis et al., 1983). By strengthening the wedge, cohesion reduces the value of the critical taper near the toe of a wedge. At a greater distance back into the wedge, the depth-dependent frictional term predominates, and the taper increases until it asymptotically approaches the value predicted by the 

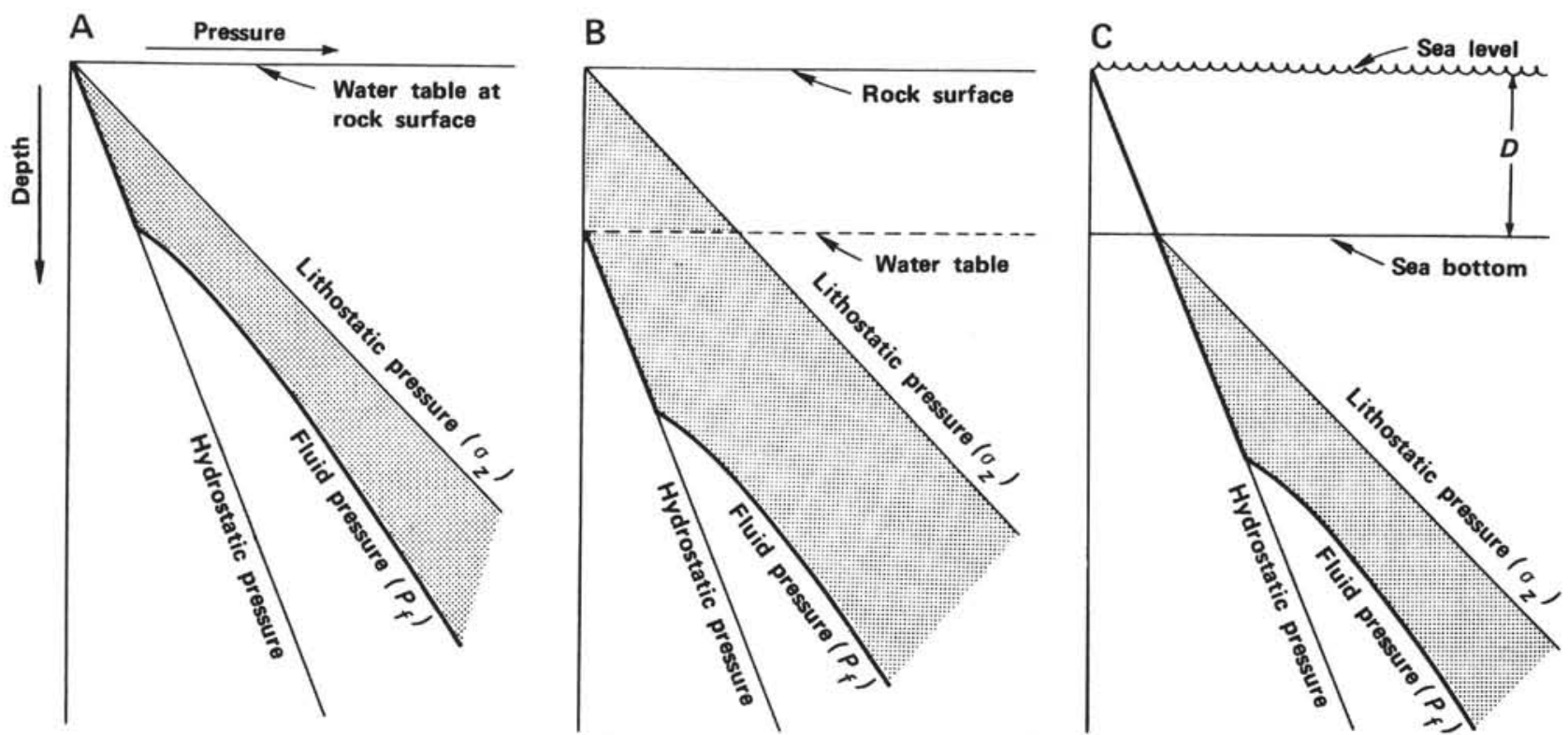

Figure 3. Relationship between fluid pressure $P_{f}$ and lithostatic overburden pressure $\sigma_{z}$ in three cases. A. Water table at surface. B. Water table below surface. C. Water table above surface (i.e., with the rock submerged, as in an accretionary wedge). In each case the Coulomb shear strength is proportional to the effective overburden, given by the difference $\sigma_{z}=\sigma_{z}^{*}-P_{f}$ and shown by shading (after Davis et al., 1983).

cohesionless theory. The wedge force balance reduces to a simple equation (Dahlen et al., in press).

$$
\alpha+\beta=\frac{\left(1-\rho_{w} / \rho\right) \beta+\left(1-\lambda_{b}\right) \tan \phi_{b}}{\left(1-\rho_{w} / \rho\right)+\mathrm{K}(1-\lambda)+\mathrm{Q}\left(C_{0} / \rho g H\right)}
$$

where $\phi_{b}$ is the friction angle along the décollement. $C_{0}$ is a measure of cohesion given by $C_{0}=S_{0}(\operatorname{ctn} \phi+$ $\cos \phi) /(1-\sin \phi)$. The constants $\mathrm{K}$ and $\mathrm{Q}$ are given by the relations

$$
\mathrm{K} \equiv \frac{2}{H} \int_{0}^{H} \frac{d z}{\cos \phi \sec 2 \psi(z)-1}
$$

and

$$
\mathrm{Q} \equiv \frac{1}{H} \int_{0}^{H} \frac{(\csc \phi-1) d z}{\csc \phi \sec 2 \psi(z)-1}
$$

The-magnitudes of the angle $\psi$ between the $\sigma_{1}$ and $\sigma_{x x}$ directions varies with depth in the wedge in a rather complicated way. However, its extreme values, which are found along the boundaries of the wedge, are easily determined. If there is the slightest amount of cohesion, then at the top of the wedge the $\sigma_{1}$ direction must be parallel to the local topography, so that $\psi_{\text {top }}=\alpha+\beta$. At the base of the wedge, the value of $\psi$ is dependent upon the strengths of both the wedge and the base

$$
\psi_{b}=\frac{\pi}{4}-\frac{\phi_{b}}{2}-\frac{1}{2} \operatorname{arcos}\left\{\frac{\sin \phi_{b}\left[1+\left(S_{0} / \sigma_{3}^{*}\right) \cos \phi\right]}{\sin \phi\left[1+\left(S_{0} / \sigma_{3}^{*}\right) \operatorname{ctn} \phi\right]}\right\}
$$

where $\left(S_{0} / \sigma_{3}^{*}\right) \simeq\left[S_{0} / \rho g H(1-\lambda)\right]$ is a dimensionless ratio which indicates the relative magnitudes of cohesion and the overburden. Calculations of $\mathrm{K}$ and $\mathrm{Q}$ based upon a linear interpolation of $\psi$ between the values de- termined for the top and bottom of the wedge yield highly accurate results (Dahlen et al., in press). For small values of $\psi$, as in a wedge with a weak $\left(\phi_{b} \ll \phi\right)$ base, Q approaches 1 and $\mathrm{K}$ approaches $K_{p}-1$, where $K_{p}=(1+\sin \phi) /(1-\sin \phi)$ is the well-known passiveearth coefficient of soil mechanics (Lambe and Whitman, 1979).

We can express the force balance in the wedge in terms of stresses and in a manner which illustrates the relative importance of gravity and horizontal compression in the wedge induced by plate tectonics.

$$
\tau_{b}=\left(\rho-\rho_{w}\right) g H \alpha+\left(1-\lambda_{b}\right) \operatorname{K} \rho g H(\alpha+\beta)
$$

The resistance to frictional sliding is balanced by two terms which correspond to the driving forces of deformation and overthrusting. The first is a glacier-sliding term which expresses the action of gravity on the sloping top surface; the corresponding force tends to produce sliding in the direction of the surface slope, regardless of the dip of the base of the wedge (Elliot, 1976). The second term is a wedge-taper-dependent resistance to horizontal compression. In all but the frontal toe regions of most thrust belts and accretionary wedges, the second term is probably larger than the first by a factor of between 3 and 10 (Davis et al., 1983). Assuming Byerlee friction on the base, then the compressive term is roughly an order of magnitude larger than the gravity gliding term in the Barbados wedge. This suggests that gravity spreading is of secondary importance compared with the effects of horizontal compression and wedge taper.

\section{Application to Barbados}

Let us apply these results to the Barbados area. The crust of the overlying plate in this region is a narrowly 
tapered wedge showing a great deal of deformation. This deformation includes numerous thrust faults verging eastward toward the deformation front (Westbrook, 1975, 1982; Moore et al., 1982). The basal décollement deepens westward at a dip of roughly $5^{\circ}$ and the mean bathymetric slope varies between zero and $2^{\circ}$. These values are reasonably typical of sediment-rich accretionary wedges around the world, but the Barbados wedge has a somewhat narrower taper than most (Fig. 4; Davis et al., 1983). The quantity of sediments available for accretion varies considerably along strike, but, in general, a cross-section bears at least a superficial resemblance to the imbricated structure that is typical of accretionary wedges (Seely et al., 1974).

There is considerable north-south variation in the tectonics of the accretionary margin. The thickness of the incoming sediment pile atop the ocean crust of the Atlantic varies by a factor of about ten: from $7 \mathrm{~km}$ near the South American continent to only $700 \mathrm{~m}$ near the Leg 78A drill sites. Insofar as this affects the rate of accretion, it affects the amount of deformation required within the wedge to maintain the taper needed for overthrusting. The Tiburon and Barracuda rises (Fig. 1) are lateral ridges which constitute inhomogeneities violating two-dimensional assumptions made to simplify understanding the mechanics of the area. Also, the convergence direction becomes increasingly oblique to the north, presumably moving the direction of the greatest principal stress axis away from the direction perpendicular to the deformation, adding another three-dimensional complication to the mechanics.

By making two assumptions, we can "predict" the fluid pressure ratio in the part of any wedge that is above the brittle-ductile transition. First, we assume that the value of the fluid pressure gradient coefficient $\lambda_{b}$ along the basal décollement is no larger than $\lambda$ in the wedge. Because the onset of the zone of high fluid pressures is often controlled by a particular stratigraphic horizon (Fertl, 1976; Suppe and Wittke, 1977) and the ba- sal décollement is likely to be located in overpressured zones, this assumption is not necessarily correct. If $\lambda_{b}$ $>\lambda$, then our predicted value of both $\lambda$ and $\lambda_{b}$ will be somewhat higher than the corresponding real values. Thus, our result gives an upper limit to the fluid pressures required for overthrusting.

The second assumption defining a "predicted" fluid pressure ratio results from the need to define the state of stress in the wedge which is close to failure. We assume that the wedge is highly fractured, so most deformation occurs along pre-existing faults. However, fractures do not exist in all possible orientations, so slip generally requires a somewhat larger stress difference $\sigma_{1}-\sigma_{3}$ than would be needed for a slip plane at the optimal orientation. Occasionally, geometric locking of structures may require fracture instead of friction, bringing into play the relatively small cohesive strength of sedimentary rocks (Hoshino et al., 1972). In Taiwan, where fluid pressures and wedge geometry are very well constrained, it has been shown that the wedge is about $20 \%$ stronger than the décollement (Davis et al., 1983). This added wedge strength probably reflects sliding along suboptimal slip planes, because the number of available slip planes is finite, as well as occasional geometric locking. Pore pressures cannot be adduced to explain this strength difference in Taiwan, where $\lambda \simeq \lambda_{b}$.

If the strengths of the Barbados wedge and décollement are similar to those in Taiwan, then the taper of this accretionary prism is consistent with relatively high values of $\lambda=\lambda_{b}$ ranging from $\sim 0.85$ in the wedge to $\sim 0.97$ near the toe. These estimates must be regarded as an upper bound; they must be reduced somewhat if the basal décollement is weaker than expected. This can be the case either if the décollement is significantly "lubricated" by weak clay minerals or if the fluid pressure coefficient at the décollement zone is much higher than in the overlying rocks. Pore pressures near Barbados are not known in as great detail as those in Taiwan. Because it is quite possible that $\lambda_{b}>\lambda$, it is conceivable that

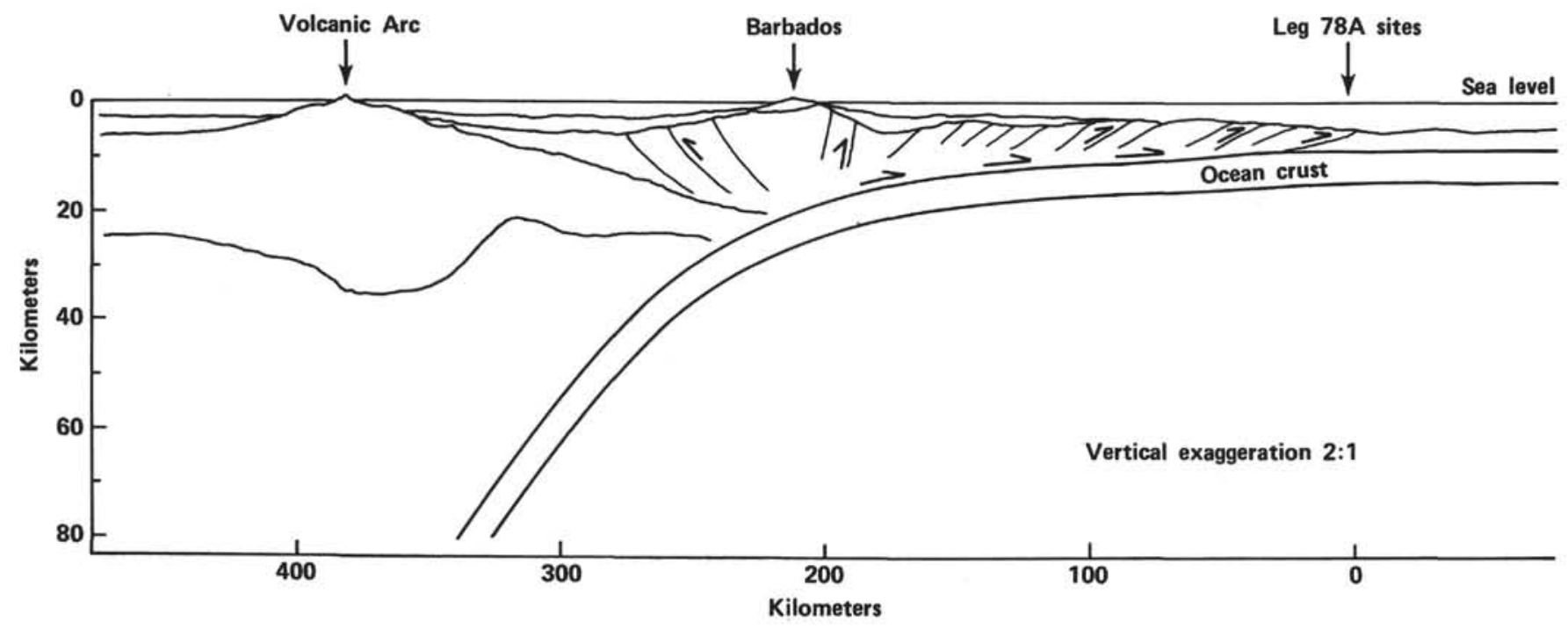

Figure 4. Diagrammatic cross-section of the Barbados area, showing the wedge geometry and the locations of Sites 541 and 542 and the island of Barbados (after Westbrook, 1975). 
there is no difference between the intrinsic strengths of the wedge and its décollement, and that the required basal weakening is a result of elevated fluid pressures.

Some scattered fluid pressure data exist for the region. Wells drilled on Barbados show elevated pore pressure, with $\lambda$ at depth near 0.8 (Moore and Von Heune, 1980). Also, a packer experiment inadvertently performed at Site 542 indicates an approximately lithostatic fluid pressure $(\lambda \approx 1)$ near the décollement. If we assume that $\lambda$ in the wedge is 0.80 , and that the friction angles in the wedge and along the basal décollement are equal, then we can match the observed taper of the wedge for $\lambda_{b} \approx 0.90$. This result is highly insensitive to the value chosen for the décollement and wedge friction angles, $\phi_{b}=\phi$. Using equation 9 and assuming Byerlee friction, we find that shear stresses along the basal décollement are very low, probably nowhere exceeding 4 $\mathrm{MPa}$. Beneath Site 541, we find values of $\tau_{b}$ ranging from $140 \mathrm{KPa}$ to $330 \mathrm{KPa}$. These low values of the shear stress are similar to the cohesion as measured in samples from that site (Marlow et al., this volume).

At the deformation front near Sites 541 and 542, the depth to basement is so small $(300-500 \mathrm{~m})$ that two complicating factors are introduced. First, the sediments may not have been sufficiently buried long enough to have compacted and consolidated. This brings the Coulomb assumption into question in a wedge as thin at its toe as the Barbados wedge. In addition, should the wedge material have a non-zero cohesive strength, the simplifying assumption that the material is cohesionless (letting us ignore the first term on the right side of equation 3) will be least appropriate at the narrow toe. A cohesionless wedge is entirely scale-independent; it can be of any desired length and still be pushed from behind, as long as it has a sufficient taper. When the cohesive strength ceases to be much smaller than the effective normal strength at the base of the wedge (as may be so near the toe), this assumption of scale-independence ceases to be appropriate.

Bathymetric profiles near the deformation front (Biju-Duval et al., 1982) show that the wedge is slightly convex near its toe. This convexity may be related to the extremely low shear strengths $(\sim 100 \mathrm{KPa})$ observed for shallow and incompletely compacted sediments at all Leg 78A sites (Marlow et al., this volume). Let us assume that the front of the wedge is perfectly plastic and has a pressure-independent shear strength. Then, an analysis identical to that described above gives the relation

$$
K^{\prime}(\alpha+\beta)=\chi-\frac{\left(\rho-\rho_{w}\right) g H \alpha}{Y}
$$

$Y$ is the wedge yield strength and $\chi$ is defined such that $\chi \cdot Y$ is the décollement strength. The value of $K^{\prime}$ is given by the expression

$$
K^{\prime}=\frac{2}{H} \int_{0}^{H} \cos 2 \psi(z) d z
$$

and is typically slightly less than 2 . With a small difference between the strengths of the wedge and its décollement (e.g., $\chi \sim 0.9$ ), and a local shear strength of the wedge material compatible with the measurements of Marlow et al. (this volume), the slight complexity of the front end of the wedge can be explained. It is likely that farther from the deformation front the wedge becomes more competent and is therefore more appropriately modeled as a Coulomb material with a pressure-dependent strength.

Given the mechanical properties of the wedge at its base, we can predict the takeoff angles of thrust faults as they step up from the basal décollement. In a noncohesive wedge which is $20 \%$ stronger than its Byerlee frictional sliding décollement, equation 8 gives a value of $12^{\circ}$ for $\psi_{b}$, the angle between the décollement and the direction of greatest compressive stress. If this difference between the strengths of the wedge and its décollement becomes large $\left(\phi \gg \phi_{b}\right)$, then $\psi_{b} \rightarrow 0$. If $\phi \approx \phi_{b}$, then $\psi_{b} \approx 45^{\circ}-\phi / 2$, giving a value of $\psi_{b}$ ranging between $25^{\circ}$ for Byerlee friction $\left(\phi \approx 40^{\circ}\right)$ and $45^{\circ}$ for an infinitely weak $(\phi \approx 0)$ wedge. Mohr-Coulomb theory suggests that the preferred orientations of fractures or slip planes should be inclined to the direction of maximum compressive stress by an angle $\theta$, given by

$$
\theta=\frac{\pi}{4}-\frac{\phi}{2}
$$

Thus, the takeoff angle of a fault at the base of the wedge should be inclined to it at an angle $\delta_{b}=\theta-\psi$. For the case of a wedge and décollement of equal strengths $\left(\phi=\phi_{b}\right)$, this means that $\theta=\psi_{b}$, so $\delta_{b}=0$, and faults stepping up from the basal décollement have a "sledrunner" geometry. At shallower depths in the wedge, where $\psi \rightarrow \alpha+\beta$, the dip $\delta$ of such a fault relative to the upper surface of the wedge approaches $\theta$, or roughtly $25^{\circ}$ for Byerlee friction. Westbrook (1982) reports thrusts with a dip of $\sim 20^{\circ}$ near the surface of the Barbados Ridge, and somewhat less at depth, consistent with a strong wedge and a slightly weaker décollement. Because wedge taper is less sensitive to absolute strength than to the relative strengths of the wedge and its base, this sensitivity of fault step-ups to the friction angle $\phi$ can provide a useful additional constraint.

The predominance of forward thrusting is probably related to the difference in takeoff angles between forward- and backward-verging thrust faults. A backwardverging thrust should step up from the décollement at an angle $\delta_{b}=\theta+\psi$, considerably more steeply than a forward-(oceanward-) verging thrust, which should step up at an angle $\delta b=\theta-\psi$. A shallow-dipping thrust (and therefore a forward-, oceanward-verging one) is probably favored for two reasons. First, a thrust with a shallow dip requires a smaller increase in potential energy for a given amount of convergence. In addition, a shallower-dipping thrust is more likely to ride for more of its length along stratigraphically controlled planes of weakness, since the overall dip of the thrust is closer to bedding. 
The front of the Barbados wedge complex accretes some, but not all, of the sediment brought into it by the subducting crust of the Atlantic Ocean. Near the Leg 78A sites, where the sediments overlying ocean basement are 700 meters thick, all but the top third or so of the sediments, which are Miocene and younger, are subducted (Biju-Duval et al., 1982). There clearly must be some sort of mechanical segregation process occurring at the frontal thrust which selects only the upper part of the oceanic sediment load for accretion and permits the remainder to subduct.

The mechanical criteria which determine that a particular stratigraphic horizon shall be the one at which the basal décollement is located are not obvious. Lithology can be an important factor. Relatively recently deposited and incompletely lithified sediments are much more likely to be plowed up by the accreting wedge than are deeper and more competent sediments (Moore, 1975). In general, the horizon that allows sliding with the least resistance will become the décollement because of energy considerations.

The presence of a relatively impermeable stratigraphic horizon below which fluid pressures are higher than above should influence the location of thrusts in accretionary wedges, much as in subaerial thrust belts. In this way, an intrinsically weaker décollement horizon could be bypassed in favor of a deeper level at which the fluid pressures are higher. On the other hand, the depth dependence of sliding resistance at shallow depths biases the choice of décollement near the deformation front toward a shallower stratigraphic horizon. At depth, where resistance may be less dependent on normal stress (and thus depth), such a bias toward the underthrusting of a large fraction of the oceanic sediments may no longer apply. Therefore, the observed underthrusting of most of the sediments at the trench in the Leg 78A area (Biju-Duval et al., 1982) does not necessarily mean that a similarly large fraction of the sediments are fully subducted. Underplating of sediments at depth farther to the west is mechanically plausible.

As new material is brought in by convergence of the two plates, compression at the toe requires that a new imbricate thrust slice be cut into the encroaching oceanic sediments. The slice is cut from the base of the existing basal thrust to the surface, at an angle controlled by the mechanical properties of the sediments. As the new sedimentary slice is added to the accretionary wedge, faults directly behind that point undergo slip in response to the slightly changed stress state, and a series of deformations occur within the wedge as a result of which the wedge taper is maintained. The addition of a new active frontal thrust may require a vertical rotation of older, rearward thrusts, giving them a larger angle of dip than they originally had. Although these older thrusts become relatively inactive, they may still need to undergo some slip to maintain the critical taper of the wedge. However, as they rotate farther from their optimum slip orientation, it becomes less likely that slip will occur entirely along the old slip planes. Instead, further imbrication along new thrusts becomes more likely.

The nature and frequency of these internal deformations are very different for thrust belts and accretionary wedges. Most thrust belts undergo geologically rapid erosion (Suppe, 1981), reducing the wedge taper. This process requires thrusting in order to restore wedge taper. In this way, deformation and seismicity can be triggered by erosion. Thus, the predominance of sedimentation over erosion on the upper surfaces of accretionary wedges contributes to making them less active than their subaerial counterparts.

Far from the toe, an accretionary wedge can be so thick that its base is below the britttle-plastic transition (Fig. 5). This transition occurs at a depth which depends upon rock type, pore pressures, and the geothermal gradient. Weakening of the base of the wedge below the

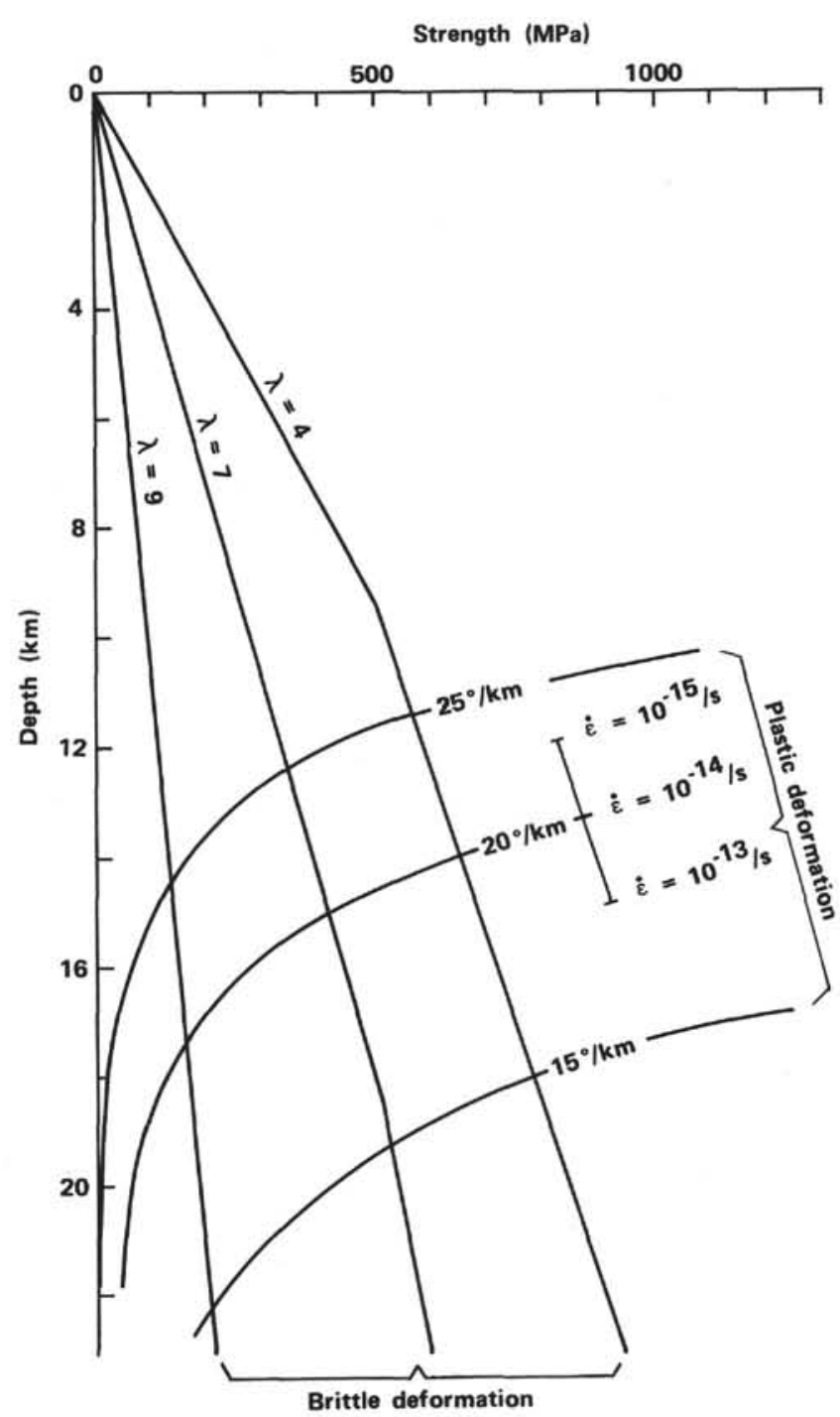

Figure 5. Rock strength, measured in terms of differential stress $\left(\sigma_{1}-\right.$ $\sigma_{3}$ ) versus depth in the earth, assuming frictional behavior (Byerlee, 1978) for shallow depths and, at depth, quartz plastic flow governed by the flow law $\dot{\epsilon}=5 \cdot 10^{-6}\left(\sigma_{1}-\sigma_{3}\right) \exp (0.19 \mathrm{MJ} \cdot$ $\left.\mathrm{mol}^{-1} / R T\right)$. The strain rate $\dot{\epsilon}$ is in units of $\mathrm{s}^{-1}, R$ is the gas constant, $T$ is the temperature in ${ }^{\circ} \mathrm{K}$, and $\left(\sigma_{1}-\sigma_{3}\right)$ is in MPa (Brace and Kohlstedt, 1980). The plastic strength has been calculated for a range of geologically reasonable strain rates and geothermal gradients. The theoretical strength is greatest at the depth of brittleplastic transition, where the brittle and plastic strengths are equal (after Davis et al., 1983). 
transition depth corresponds to a reduced value of $\tau_{b}$ in equation 9. This in turn leads to a lower value of the critical taper $(\alpha+\beta)$ on the right side of that equation. In other words, where the base of the wedge is weakened by high temperatures at depth, the wedge can stably ride over the downgoing plate, even though it has a smaller taper than would otherwise be required. This effect of the brittle-plastic transition is consistent with the flattening out of the upper surface observed at the thick end of many large thrust belts and accretionary wedges.

The combination of plasticity at depth and steepening of the dip of the basal décollement should result in a western limit to the critically tapered region of the Barbados wedge. To the east (Fig. 6), the wedge should be at or very near horizontal compressive failure.

\section{Borehole Stability}

Difficulties have often been experienced in drilling boreholes in accretionary wedges. These difficulties take the form of abnormal pore pressures (Moore and von Huene, 1980; Hottman et al., 1979; J. Harms, personal communication, 1982) and hole collapse. Both of the Leg 78A sites on the accretionary wedge (Sites 541 and 542) showed signs of borehole instability.
The origin of abnormal pore pressures in accretionary wedges has been the subject of some debate. Proposed mechanisms include methane generation, aquathermal pressuring, and phase changes, any of which might produce overpressures by increasing the fluid volume (Moore and von Huene, 1980). Alternative mechanisms involve the loading of additional overburden atop sufficiently impermeable rock. This loading can result from either rapid sedimentation, as in the Louisiana Gulf Coast (Fertl, 1976), or from tectonically generated loading and horizontal compression. Thrust faulting in active accretionary wedges and in fold-and-thrust belts is well suited to producing such tectonic loading. Considerable evidence exists for high fluid pressures beneath Barbados (Moore and von Huene, 1980) and at Site 542.

Borehole instability is a subject of considerable concern in drilling near the base of the trench slope (Moore and von Huene, 1980). Let us consider the problem of borehole collapse in terms of the borehole acting as a stress concentrator in a marginally stable environment, as implied by Coulomb wedge theory, with the rock close to compressive failure. Let us model the borehole as a vertical cylindrical hole drilled into an elastic halfspace. This hole acts as a stress concentrator, altering

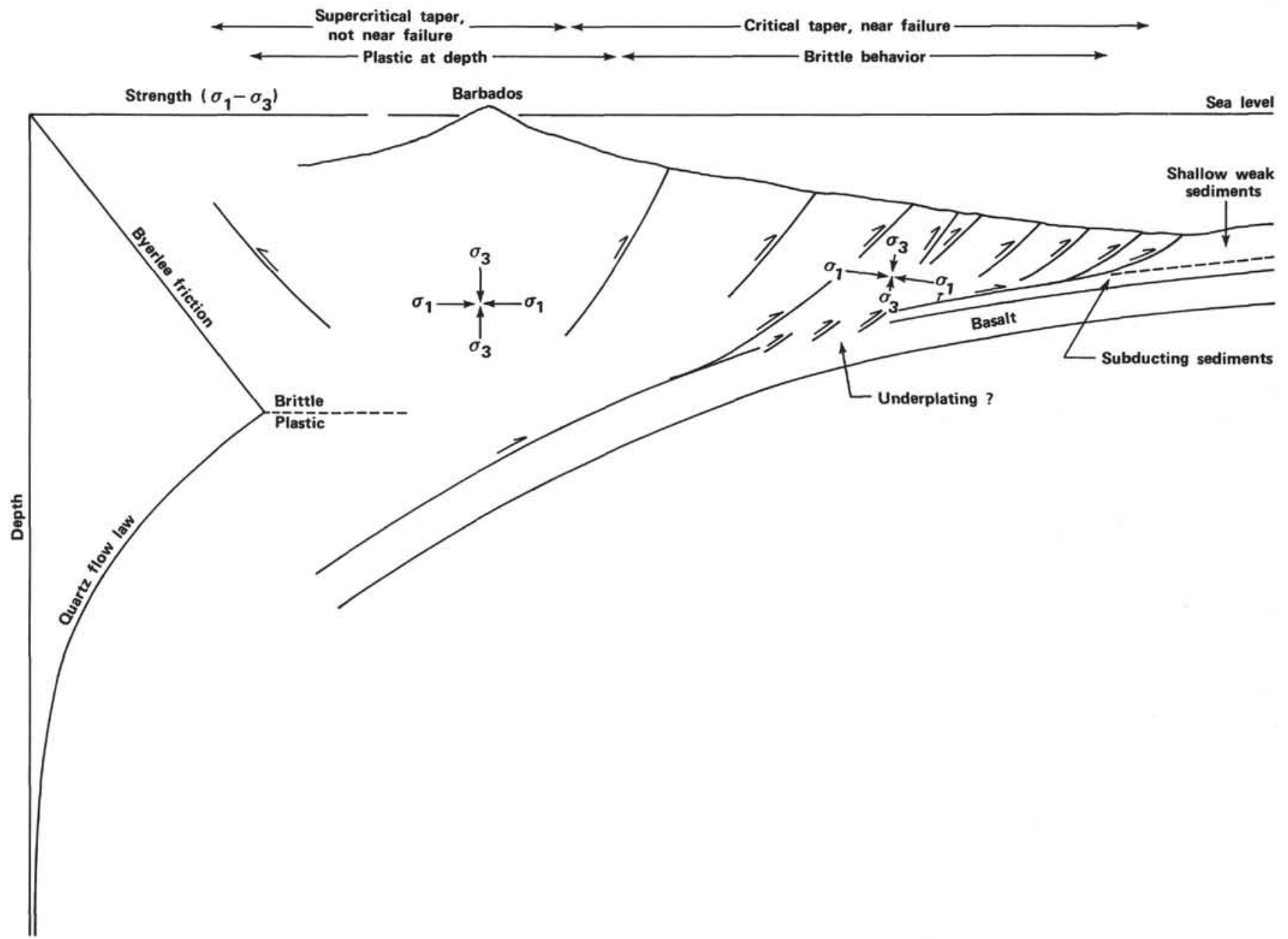

Figure 6. Schematic diagram (with great vertical exaggeration) illustrating implications of the compression-dominated mechanics for the Barbados wedge. Note that differential stresses are higher near the deformation front than near Barbados. 
the state of stress in its vicinity (Hottman et al., 1979; Hubert and Willis, 1959). We ignore edge effects (the borehole is much longer than it is wide) and fluid-flow effects (the high permeability observed at Site 542 was a fracture permeability, and the sediments themselves are highly impermeable). The results of equation 8 allow us to assume that $\psi \approx 0$, so that one of the far-field principal stress axes (in this case $\sigma_{3}$ ) is essentially vertical. The state of stress expressed in cylindrical coordinates, using the convention that compressive stresses are positive, is (Haimson, 1968)

$$
\begin{aligned}
\sigma_{r r}= & \frac{\left(\sigma_{1}+\sigma_{2}\right)}{2}\left(1-R^{-2}\right)+\frac{\left(\sigma_{1}-\sigma_{2}\right)}{2}\left(1+3 R^{-4}-4 R^{-2}\right) \cos 2 \theta \\
& +P_{w} R^{-2} \\
\sigma_{\theta \theta}= & \frac{\left(\sigma_{1}+\sigma_{2}\right)}{2}\left(1+R^{-2}\right)-\frac{\left(\sigma_{1}-\sigma_{2}\right)}{2}\left(1+3 R^{-4}\right) \cos 2 \theta \\
& -P_{w} R \\
\tau_{r} \theta= & \frac{\left(\sigma_{1}-\sigma_{2}\right)}{2}\left(1-3 R^{-4}+2 R^{-2}\right) \sin 2 \theta \\
\sigma_{v v}= & \sigma_{3}-2 v\left(\sigma_{1}-\sigma_{2}\right)\left(R^{-2}\right) \cos 2 \theta
\end{aligned}
$$

for any point at a distance $R$ borehole radii from the center of a borehole, in a direction at an angle $\theta$ from the direction of undisturbed maximum compressive stress, where $\sigma_{r r}, \sigma_{\theta \theta}$, and $\sigma_{v v}$ are the components of stress in the $r, \sigma$, and vertical axis directions, respectively. $P_{w}$ is the water pressure in the borehole and $\nu$ is Poisson's ratio. Note that the stress concentration effect is extremely localized near the hole. The effects of the drilling procedure on the sediments very close to the borehole may affect our ability to predict both a failure criterion and the elastic behavior required for this stress analysis. However, if predicted failure extends well beyond the immediate vicinity of the borehole wall, we may feel safe in predicting that fracture of the sediments and collapse of the borehole will take place.

Assuming that we have a reasonable idea of the conditions in the borehole at Site 541, with an ambient stress state close to horizontal compressive failure, let us consider the stability of a borehole. At the borehole wall (where $R=1$ ), the stress state becomes

$$
\begin{aligned}
& \sigma_{r r}=P_{w} \\
& \sigma_{\theta \theta}=\sigma_{1}+\sigma_{2}-2\left(\sigma_{1}-\sigma_{2}\right) \cos 2 \theta-P_{w} \\
& \tau_{r} \theta=0 \\
& \sigma_{v v}=\sigma_{3}-2 \nu\left(\sigma_{1}-\sigma_{2}\right) \cos 2 \theta
\end{aligned}
$$

It has been pointed out (Hottman et al., 1979) that changes in $\boldsymbol{P}_{w}$, the pressure of the mud (in our case water) in the borehole, can allow different types of borehole wall failure to occur. The most familiar of these is hydrofracture (Hubbert and Willis, 1957), which results when high mud weights in the hole make $P_{w}$ large enough to reduce $\sigma_{\theta \theta}$ to the point of tensile failure at $\theta=0$ and $180^{\circ}$. This produces a vertical fracture perpendicular to the borehole wall and $\sigma_{2}$ direction.

Other sorts of failure are possible in a borehole. The fact that the boreholes at Sites 541 and 542 were filled with water instead of mud makes $P_{w}$ too small for initiation of tensile failure in the borehole wall. Instead, we expect that the state of stress at all points on the wall of one of these boreholes should be such that the direction of least compressive stress is the radial $\sigma_{r r}$ direction. A short distance past the borehole wall, the vertical stress $\sigma_{v v}$ attains its far-field status as the least compressive stress, and fractures rotate to a more nearly horizontal orientation. However, in the immediate vicinity of the borehole, the stress state is such that failure takes the form of tangential compression of the wall at $\theta=90^{\circ}$ and $270^{\circ}$. If the hole is filled with water, then $P_{w}$ (and thus $\sigma_{r r}$ at $R=1$ ) can be small enough that the effective radial stress $\sigma_{r r}^{*}=\sigma_{r r}-P_{f}$ can become sufficiently tensile as to overcome the tensile strength of the material. The result, as described by Hottman et al. (1979) for a borehole drilled in the Gulf of Alaska, is an infall of wall material into the hole and collapse of the hole in the direction of the far-field maximum compressive stress. Here, as in the Alaskan case, the $\sigma_{1}$ direction is roughly perpendicular to the trench or deformation front axis. For either a depth-dependent Coulomb or depthindependent plastic failure criterion, the stress concentration at and near a borehole wall will be sufficient to initiate failure (Fig. 7).

Given the near-failure state of stress which we expect to exist before drilling, collapse of the hole caused by distortion of the stress field in the vicinity of the hole is to be expected for any reasonable failure criterion. Thus any possible non-Coulomb behavior of sediments which are either too deep and hot or extremely shallow and not fully lithified (as is largely the case at Sites 541 and 542) will not seriously affect this conclusion.

In an accretionary prism having the state of stress predicted by the compressive wedge theory (equation 4), borehole instability is very likely. One major exception to this rule would be holes drilled in ponded sediments partially decoupled from the thrusting mass of sediments beneath, in that they have not acquired the large horizontal stresses found in the wedge on which they have been deposited. Another locale where boreholes in an actively accreting prism might be stable would be one with supercritical taper (greater than neecessary to be pushed) produced by sedimentation or underplating, or one very far in the back of the wedge, where the basal décollement is steep and possibly thermally weakened. It is also possible for an entire wedge to have become supercritical because of increased pore pressure (either increased $\lambda_{b}$ or matching increases in both $\lambda_{b}$ and $\lambda$ ) or, alternatively, because of decreased basal friction, resulting from a change over time in the mechanical characteristics of subducted material. Such a supercritical wedge would, like a supercritical part of an otherwise 
A

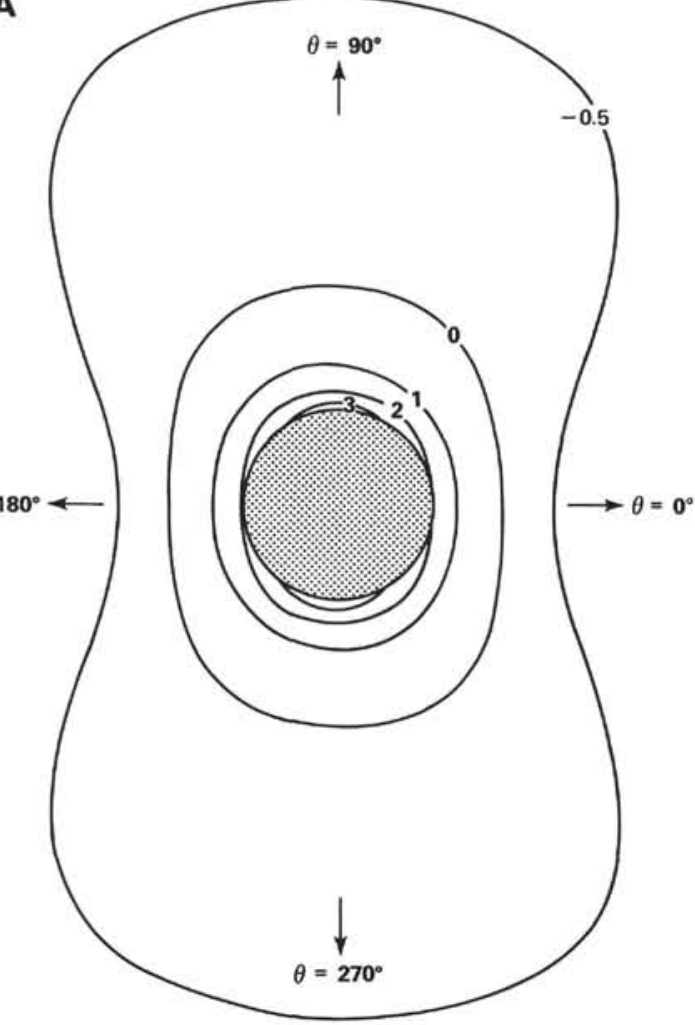

B

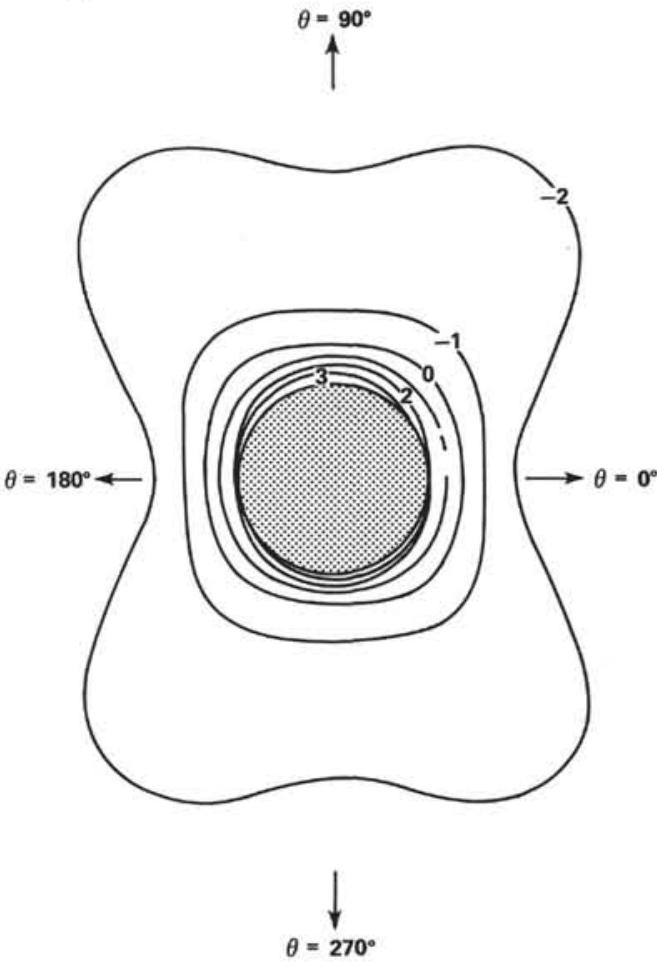

Figure 7. Stability of the region near a borehole under conditions similar to those at Sites 541 and 542 . The difference (in $\mathrm{MPa}$ ) between maximum shear stress and that required for failure (negative numbers indicating instability) is plotted for the region around the hole. A. Plot for a Coulomb Failure Criterion. B. Plot for a perfectly plastic material in which internal friction $\phi=0$. It is assumed that the sediment density $=1.8 \mathrm{~g} \cdot \mathrm{cm}^{-3}$, Poisson's ratio $=0.4$, the borehole is filled with water, and the far-field stress difference $\sigma_{1}-\sigma_{3}$ at this point 300 meters below the surface beneath $5 \mathrm{~km}$ of water is $80 \%$ of that required for failure.

critical wedge, have a state of stress different from that predicted on the assumption that the wedge is everywhere in compressive failure.

\section{SUMMARY}

The overall geometry and mechanics of the Barbados accretionary wedge are analagous to those of a wedge of soil being pushed by a bulldozer. The sediments in the accretionary prism deform until they have a sufficiently large wedge taper that the wedge, if left undisturbed, could be pushed over the basal décollement without additional deformation. As new material is accreted, the wedge must deform to maintain this critical taper. The magnitude of this taper is a function of numerous parameters, including pore pressure in the sediments. We cannot unambiguously resolve both fluid pressures and the relative strengths of the wedge and its base. We can confirm, however, that the Barbados wedge resembles that of Taiwan in having a gross taper consistent with a base weaker by only a small amount than the rocks in the wedge itself. In Taiwan, the strength difference is attributable to cohesion within the wedge, as pore pressures do not preferentially weaken the basal décollement to a significant degree. In the Barbados wedge, the sparse available pore-pressure data leave open the possibility that pore pressures higher along the basal décollement than in the wedge play an important role. The observed taper is consistent (equations 5 and 6) with a décollement of the same intrinsic strength as the wedge, but with a fluid pressure ratio of $\lambda_{b} \approx 0.9$, as opposed to $\lambda \approx 0.8$ in the wedge, or with very high values of $\lambda=$ $\lambda_{b}$, from $\sim 0.85$ near Barbados to $\sim 0.97$ near the toe. This result suggests that décollement shear stresses are between 0.14 and $0.33 \mathrm{MPa}$ near Site 541 .

Assuming that the wedge is near its critical taper, stress orientations can be predicted for the wedge. This method is not particularly sensitive to the absolute magnitudes of stresses and rock strengths. It is very sensitive, however, to the ratio of the strengths within the wedge and along the basal décollement. A borehole drilled into an accretionary wedge that can be represented as an elastic half-space near horizontal compressive failure should be unstable and tend to collapse. This is in accord with the observations at Sites 541 and 542.

I have suggested that there exist simple relationships between the shape and compressive mechanics of accretionary wedges. An understanding of their mechanics permits quantification of the relationships between pore pressures, states of stress, and the stability of boreholes in accretionary wedges. These relationships are consistent with the results of Leg 78A, and suggest that the Barbados accretionary wedge complex is deforming under horizontal compression resulting from shear stresses generated as it overides its basal décollement. 


\section{ACKNOWLEDGEMENTS}

I would like to acknowledge helpful discussions with Sean Solomon, John Suppe, and Tony Dahlen. Casey Moore gave me a copy of a cross-section which proved very useful. The reviewers of this paper, Graham Westbrook and Donald Seely, made many good suggestions, for which I am grateful. This work was supported by the Division of Earth Sciences, National Science Foundation grant EAR78-12936.

\section{REFERENCES}

Biju-Duval, B., Le Quellec, P., Mascle, A., Renard, V., and Valery, P., 1982. Multibeam barythmetric survey and high resolution seismic investigations on the Barbados Ridge complex (Eastern Caribbean): A key to the knowledge and interpretation of an accretionary wedge. Tectonophysics, 86:275-304.

Brace, W. F., and Kohlstedt, D. L., 1980. Limits on lithospheric stress imposed by laboratory experiments. J. Geophys. Res., 85: 6248-6252.

Byerlee, J., 1978. Friction of rocks. Pure Appl. Geophys., 116:615-626.

Chapple, W. M., 1978. Mechanics of thin-skinned fold-and-thrust belts. Geol. Soc. Am. Bull., 89:1189-1198.

Dahlen, F. A., Suppe, J., and Davis, D. M., in press. Mechanics of fold-thrust belts and accretionary wedges (continued): cohesive Coulomb theory. J. Geophys. Res.

Davis, D. M., and Suppe, J., 1980. Critical taper in mechanics of fold-and-thrust belts. Geol. Soc. Am. Abstracts with Programs, 12:410. (Abstract)

Davis, D. M., Suppe, J., and Dahlen, F. A., 1983. Mechanics of foldand-thrust belts and accretionary wedges. J. Geophys. Res., 88: 1153-1172.

Elliot, D., 1976. The motion of thrust sheets. J. Geophys. Res., 81: 949-963.

Fertl, W. H., 1976. Abnormal Formation Pressures: New York (Elsevier).

Goetze, C., 1978. The mechanism of creep in olivine. Philos. Trans. R. Soc. London, Ser. A, 288:99-119.

Haimson, B., 1968. Hydraulic fracturing in porous and nonporous rock and its potential for determining in-situ stresses at great depth [Ph.D. dissert.]. University of Minnesota, Minneapolis, Minnesota.

Heard, H. C., and Carter, N. L., 1968. Experimentally induced "natural" intragranular flow in quartz and quartzite. Am. J. Sci., 266: $1-42$.

Hoshino, K., Koide, H., Inami, K., Iwamura, S., and Mitsui, S., 1972. Mechanical properties of Japanese Tertiary sedimentary rocks under high confining pressures. Geol. Surv. Japan Rept. 244.

Hottman, C. E., Smith, J. H., and Purcell, W. R., 1979. Relationship among earth stresses, pore pressure, and drilling problems offshore Gulf of Alaska. J. Pet. Tech., 1477-1484.

Hubbert, M. K., and Rubey, W. W., 1959. Role of fluid pressure in mechanics of overthrust faulting Pt. 1. Mechanics of fluid-filled porous solids and its application to overthrust faulting. Geol. Soc. Am. Bull., 70:115-166.

Hubbert, M. K., and Willis, D. G., 1957. Mechanics of hydraulic fracturing. Trans. Am. Inst. Min. Eng., 210:153-166.

Kirby, S. H., 1980. Tectonic stresses in the lithosphere: constraints provided by the experimental deformation of rocks. J. Geophys. Res., 85:6353-6363.

Lambe, T. W., and Whitman, R. V., 1979. Soil Mechanics, SI Version: New York (Wiley).

Meissner, R., and Strehlau, J., 1982. Limits of stresses in continental crusts and their relation to the depth-frequency distribution of shallow earthquakes. Tectonics, 1:57-72.

Minster, J. B., and Jordan, T. H., 1978. Present-day plate motions. J. Geophys. Res., 83:5331-5354.

Moore, J. C., 1975. Selective subduction. Geology, 3:530-532.

Moore, J. C., Biju-Duval, B., Bergen, J. A., Blackinton, G., Claypool, G. E., et al., 1982. Offscraping and underthrusting of sediment at the deformation front of the Barbados Ridge: Deep Sea Drilling Project Leg 78A. Geol. Soc. Am. Bull., 93:1065-1077.

Moore, J. C., and von Huene, R., 1980. Abnormal pore pressure and hole instability in forearc regions: A preliminary report. Unpublished Report for the Ocean Margin Drilling Program, JOIDES.

Paterson, M. S., 1978. Experimental Rock Deformation: The Brittle Field: New York (Springer-Verlag), pp. 16-50.

Pfiffner, O. A., and Ramsay, J. G., 1982. Constraints on geological strain rates: Arguments from finite strain states of naturally deformed rocks. J. Geophys. Res., 87:311-321.

Seely, D. R., Vail, P. R., and Walton, G. G., 1974. Trench slope model. In Burk, C. A., and Drake, C. L. (Eds.). The Geology of Continental Margins: New York (Springer-Verlag), pp. 249-260.

Smoluchowski, M. S., 1909. Some remarks on the mechanics of overthrusts. Geol. Mag. New Ser., 6:204-205.

Suppe, J., 1981. Mechanics of mountain building and metamorphism in Taiwan. Geol. Soc. China Mem. 4, 67-89.

Suppe, J., and Wittke, J. H., 1977. Abnormal pore-fluid pressures in relation to stratigraphy and structure in the active fold-and-thrust belt of northwestern Taiwan. Pet. Geol. Taiwan, 14:11-24.

Timoshenko, S., and Goodier, J. N., 1951. Theory of Elasticity (2nd ed.): New York (McGraw-Hill).

Westbrook, G. K., 1975. The structure of the crust and upper mantle in the region of Barbados and the Lesser Antilles. Geophys. J. R. Astron. Soc., 43:201-242.

1982. The Barbados Ridge complex: tectonics of a mature forearc system. In Leggett, J. K. (Ed.), Trench-forearc Geology: Sedimentation and Tectonics on Modern and Ancient Active Plate Margins, Geological Society Special Publication No. 10: Boston (Blackwell Scientific Publications), pp. 275-290.

Date of Initial Receipt: September 21, 1983

Date of Acceptance: May 3, 1983 